\title{
DIVISION OF ENTERPRISES AND THEIR MANAGEMENT STRATEGIES IN RELATION TO INDUSTRY 4.0
}

\author{
Vrchota, J., Vlčková, M., Frantíková, Z.
}

Jaroslav Vrchota / University of South Bohemia in České Budějovice, Faculty of Economics, Department of Management, Studentská 13, České Budějovice, Czech Republic. Email: vrchota@ef.jcu.cz.

Miroslava Vlčková / University of South Bohemia in České Budějovice, Faculty of Economics, Department of Accounting and Finance, Studentská 13, České Budějovice, Czech Republic. Email: mvlckova02@ef.jcu.cz.

Zuzana Frantíková / University of South Bohemia in České Budějovice, Faculty of Economics, Department of Law, Studentská 13, České Budějovice, Czech Republic. Email: zfrantikova@ef.jcu.cz.

\begin{abstract}
In today's turbulent times, businesses must cope with an increasing focus on digital technology, automation and robotics systems. It represents the fourth industrial revolution, called Industry 4.0. The goals of Industry 4.0 are achieving higher levels of operational efficiency and productivity, as well as a higher level of automation. Concerning Industry 4.0, therefore, not only the technological aspect but also the size of the organization, the scope of business by industry and other elements are considered and analyzed based on MannWhitney $U$ test and Fisher test. According to statistical analysis, it was found that the size of the company affects its relationship to Industry 4.0, and we can say that the larger the business, the more it is affected by Industry 4.0. This influence was manifested primarily in companies operating in the field of commercial activities, or Agriculture and Construction. In terms of the relationship between the written strategy and Industry 4.0, it can be stated that the link between them has occurred in small and medium-sized enterprises operating in the areas of Professional and Administrative Activities, Manufacturing and Wholesale, Transport and Accommodation. In contrast, this effect has not been proven in micro-enterprises.

Implications for a Central European audience: The paper primarily deals with the analysis of the relationship between enterprise size and Industry 4.0 and the study of the relationship between the division of enterprises by industry in relation to CZ-NACE. A significant difference was found between the enterprises affected and unaffected by Industry 4.0 when evaluating the size of the enterprise. Enterprises involved by Industry 4.0 employ more workers, which may be due to the introduction of automation and robotic automation, which means the initial phase. As the results further show, the written strategy is mostly the domain of medium-sized enterprises, with only $29 \%$ of micro-enterprises and $41 \%$ of small enterprises having it defined.
\end{abstract}

Keywords: enterprise size; CZ-NACE; Industry 4.0; strategy; management of the company JEL Classification: L25, M10, O33 


\section{Introduction}

The concept Industry 4.0 appeared for the first time in 2011 in Germany, when representatives of commerce, universities and politicians started to promote the idea to the strengthening of the competitiveness of the industry. The new idea took hold, and that is why in industrially advanced countries, the development is currently heading towards the fourth stage of industrialization, and after mechanization, electrification and information, this fourth stage was called Industry 4.0 (Zhou, Liu, \& Zhou, 2015; Schuh, Potente, Wesch-Potente, Weber, \& Prote, 2014). These are fully mechanized and automated systems based on advanced digitization, a combination of Internet and future-oriented technologies and machine intelligence (Lasi, Fettke, Kemper, Feld, \& Hoffmann, 2014, Obitko \& Jirkovský, 2015). However, the impact of the Fourth Industrial Revolution is more widespread and affects the engineering processes of SMEs. It means that the potential for productivity growth lies mainly in improving brain work and decision-making processes (Schuh, Potente, WeschPotente, Weber, \& Prote, 2014).

The digital world has become an integral part of our lives. Digitalization of the production may create new commercial models and also new commercial chains. The main focus of Industry 4.0 is connected with the virtual area, so new concepts for information technologies are requested. Under Industry 4.0, people and machines will collaborate using cognitive technologies in industrial environments. Intelligent machines will be able to help people do most of the work with speech recognition, computer vision, machine learning and advanced synchronization models (Schlechtendahl, Keinert, Kretschmer, Lechler, \& Verl, 2015). Advanced learning models for robots are, therefore crucial for people and machines to develop skills that complement each other under any working conditions (Zhong, Xu, Klotz, \& Newman, 2017). From the perspective of robotization, the new companies do not focus only on performance and automatization but also on the search of the interconnection of the robotic and human work (Bordel, 2017), on the emotions and effective and discreet acts of the robot that is placed at the workplace next to a human being (Mattsson, 2016). Researchers should aim to create and optimize innovative solutions for different types of businesses in order to support their uptake (Modrak, Soltysova, \& Poklemba, 2019).

Increasing organizational complexity in production cannot be managed in the form of centralization (Frazzon, Hartmann, Makuschewitz, \& Scholz-Reiter, 2013) and at the same time without a properly formulated strategy. Decision-making will then move to decentralized instances, where at individual decentralized levels, operative and strategic decisions will be taken either by workers or using artificial intelligence methods. (Stock \& Seliger, 2016).

Most literature (especially in the Czech Republic) mainly deals with the technical side of Industry 4.0, yet they do not pursue management approaches, organizational culture and structure. However, the implementation of Industry 4.0 does require continual formation and innovations depending on the capabilities of human being, organization (Mohelska \& Sokolova, 2018) and undoubtedly on the type of the enterprise and management conceptions. Frequently, researchers and companies have different views on the concept and vision of Industry 4.0 (Pereira \& Romero, 2017).

The aim of this paper is to evaluate the dependence of Czech companies regarding their size determined by the number of employees and the dependence of the industry in which the companies operate in comparison with the development in the area of Industry 4.0. A partial 
goal is to evaluate these impacts in companies with a formulated management strategy. The paper is only focused on micro, small and medium enterprises.

\section{Literature review}

As it was formerly written, the main ideas about Industry 4.0 date back to 2011 (Kagermann, Lukas, Wahlster, 2011). However, the industrial robotization has been used in a wide range of applications since 1965 (Esmaeilian, Behdad, \& Wang, 2016).

The first stage of industrialization - mechanization - happened at the end of the 18th century and was based on water and steam. First mechanical loom appeared in 1784. The second stage of industrialization is dated to the beginning of the 20th century when the mechanization in mass production is implemented, and therefore conveyor belts are used. This stage is connected with the names Henry Ford and in the Czech Republic with the name of Tomás Bat'a. The third stage of industrialization is linked with the development of the area in electronics, information technologies and digital automatization of production and it is still lasting (Bahrin, Othman, Azli, \& Talib, 2016).

However, we should not only look back into the past, the study "The Future of Employment: How Sensitive is the Automation Work "reached the conclusion that by $203347 \%$ of working places in developed economies is highly endangered right due to the automatization (Frey and Osborne, 2017).

Industry 4.0 is bringing a new wave of smart factories that will determine the future competitiveness of manufacturing companies. It is anticipated that this advantage will primarily be for medium and macro enterprises. Production automation will bring many benefits, whether time or quantity, including allowing data collection, integration and analysis to an extent not previously recorded (Obitko \& Jirkovský, 2015). This should improve both economic growth and competitiveness, but also bring more creativity, greater resource efficiency, greater compatibility with work commitment and working conditions.

According to Prause (2015) the proofs of successful enterprises show that new commercial models are focused more on services, innovations and network approaches than on traditional concepts of industry enterprises. As a result, the industry companies must reassess and renovate commercial models and organizational structures regarding Industry 4.0.

According to Rüßmann et al. (2015) it has been found that this fourth wave of technological progress will bring benefits in these four areas:

- $\quad$ productivity - over the next five to ten years, Industry 4.0 will be hired by more businesses, which increases productivity in manufacturing industries. Improvements in cost productivity, excluding material costs, will range from 15 to 25 per cent,

- $\quad$ revenue growth - Industry 4.0 will also lead to revenue growth. While manufacturers' demand for improved equipment and new data applications will grow, this area will generate additional revenue,

- $\quad$ employment - growth that stimulates productivity and income growth will lead to a $6 \%$ increase in employment over the next ten years and may increase even more in the mechanical engineering sector - up to $10 \%$. However, different skills will be 
required. In the short term, this trend will lead to greater automation and some oftenunskilled workers, who perform simple, repetitive tasks, will be replaced by robots. At the same time, the increasing use of the software will increase the demand for employees with competence in software development and information technology,

- $\quad$ investment - adapting production processes to integrate Industry 4.0 will require billions of euros.

The most significant reasons for the implementation of Industry 4.0 result from the abovementioned areas. The enterprises that continue in automatization and robotization may expect the decrease in costs, an increase of productivity and of quality production, the increase of revenues etc. All above-mentioned aspects can bring an increase in economy. However, automatization and robotization are not suitable for anybody. In 2014 , a survey was conducted in a total of 518 German industrial companies entitled "Industry 4.0 - a revolution in work organization ". In terms of the size of enterprises, measured by a number of employees, one-third of respondents (33\%) work for companies with less than 250 employees, while $60 \%$ work for macro companies. Respondents were equally divided into groups with manual production (30\%), hybrid production (34\%) and automated or highly automated production (26\%) (Schlund, Hämmerle, \& Strölin, 2014). It means that the implementation of the elements of Industry 4.0 is not suitable for all enterprises; it is rather used by medium and big size enterprises. This is given that fact that the micro-enterprises do not have financial sources and possibilities that may enable them to use automatic systems and the rentability of the inserted capital was too long.

Figure 1 | The level of automation in the production environment

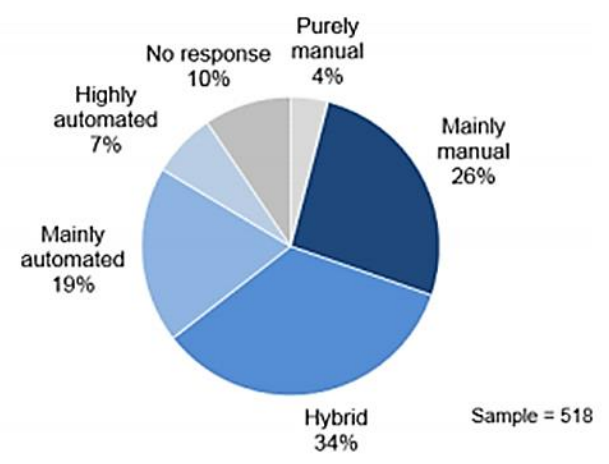

Source: Schlund, Hämmerle, \& Strölin (2014)

Only $6 \%$ of those respondents believe their company is fully ready for Industry 4.0 . In contrast, a $55 \%$ majority of companies have yet to begin work to prepare for Industry 4.0. An explicit Industry 4.0 strategy already exists in only $29 \%$ of the companies surveyed. Only $22 \%$ of companies have a separate budget dedicated to the issue of Industry 4.0 (ranging from $0.01 \%$ to $20 \%$ of annual sales) (Schlund, Hämmerle, \& Strölin, 2014).

Botha (2018) represents an approach to how to control an enterprise for future-readiness and how to evaluate technology, behaviour and event levels as factors affecting Industry 4.0. SMEs lack the skills and knowledge to carry out the process of transition to Industry 4.0 autonomously (Wienbruch, Leineweber, Kreimeier, \& Kuhlenkoetter, 2018). Within an 
intelligent factory, products can communicate with their environment and influence the organization of production systems (Brettel, Friederichsen, Keller, \& Rosenberg, 2014). The integration of information and communication technologies into production processes generates a large volume of different data. The development of data processing algorithms will, therefore be one of the main challenges (Lu, 2017).

Trends in increasing process efficiency and reducing environmental impact are stimulating the use of industrial robotics in Manufacturing (Esmaeilian, Behdad, \& Wang, 2016). Many businesses are currently confronted with the challenge that technologies, such as information or communication, are available, (Schmidt et al., 2015), but individual employees are not ready to use Industry 4.0 successfully (Prinz et al., 2016). Businesses should also focus on human capital when formulating their strategic plans. The challenge for the information technology industry is, therefore, to design a working environment that not only attracts but also retains qualified human capital (Nayak \& Suhan, 2017). In the future robots and humans will work side by side (Gilchrist, 2016).

SMEs play a crucial role in the Czech economy; they are a source of development of cities, regions and the state itself. Small and medium-sized enterprises represent $99,84 \%$ of all business entities (Ministry of Industry and Trade, 2011). The European Union defines enterprises as micro, small and medium-sized enterprises according to the number of employees, turnover and total assets. A micro-enterprise is one which employs less than ten persons and whose annual turnover or annual balance sheet total does not exceed 2 million euros. A small enterprise is characterized as having less than 50 employees and whose annual turnover or annual balance sheet total does not exceed 10 million euros. The medium-sized enterprise employs less than 250 people and has an annual turnover or annual balance sheet total, not exceeding 50 million euros (European Commission, 2006).

Statistical data underline this position and indicate that SMEs employ $2 / 3$ of the employees. Therefore, their development is strongly linked to the development of local economies and to future developments in Industry 4.0. Strategy plays a crucial role here, as these companies do not have sufficient access to capital, as large firms, and therefore have to choose appropriate strategies to maintain competitiveness (Entrialgo, 2000). Strategic management is a set of instructions, decisions and activities which are essential to achieve competitive advantage and secure a higher than average returns of the company (Hitt, Ireland and Roskisson, 2011). Porter (1996) says that strategy is the creation of a unique and valuable position, involving a different set of activities. Mintzberg and Quinn (1991) stress the importance of a written strategy for better grasping and implementing it.

Many authors deal with the relation to Industry 4.0 and with the organizational structure, such as Stock, \& Seliger (2016), Frazzon, Hartmann, Makuschewitz, \& Scholz-Reiter (2013), Trompisch (2017) and others. However, it can be assumed that companies with a larger and more sophisticated organizational structure will also have more employees (Stock, \& Seliger, 2016).

Industry 4.0 affects not only all industry sectors but also the concepts of an enterprise as such. It is necessary for the enterprises to assess well whether they need to implement automatization and robotization and whether it is suitable for them or not. It is possible that enterprises will not be prepared for this change that they will not know their (financial, management, organizational, and human) possibilities that they can get into existential 
problems. Enterprises should analyze and assess well their possibilities (Hatammimi \& Krisnawati, 2018).

Many factors will affect the implementation of Industry 4.0 elements such as size of the enterprise, number of employees, sector in which the enterprises do business, financial indicators such as for e. g. amount of equity and liabilities, fixed assets, ways of financing. In this paper we will focus from our point of view on the most important ones, namely the size of the company analyzed according to the number of employees and according to the methodology of the European Commission (2006), divided into micro, small and medium enterprises, further on the influence of CZ NACE industries and the formulation of strategic goals in individual companies. Obviously, another approach to Industry 4.0 will have a microenterprise, other small and medium enterprise and totally different approach to Industry 4.0 will be implemented by macro enterprises.

\section{Methodology}

The aim of the paper is to analyze data obtained from 1018 companies from the Czech Republic and their relationship to Industry 4.0. The data were collected by means of questionnaire surveys, when a proportional sample of 44,000 enterprises in terms of the business sector was created to match the distribution in the Czech Republic, subsequently, in 2018 , data from 1018 companies were obtained with a return of less than $2 \%$.

The enterprises were divided into micro-enterprises (213), small enterprises (493) and medium-sized enterprises (312) for research purposes according to the methodology of the European Commission (2006) They were further divided into six categories according to the business sector using the CZ-NACE methodology and the seventh category, other where sectors with less than $3 \%$ share were incorporated. At the same time, the enterprises were structured according to a written strategy, where it was shown that 461 enterprises had it, against 567 enterprises without a written strategy. Subsequently, the individual relationships of these factors were analyzed with a question focused on the relationship of companies to Industry 4.0 ("Are you or will you be affected by Industry 4.0 in the next five years? ") Of the total, $62 \%$ of companies feel that they are or they will be affected by Industry 4.0 in the next five years. As a statistical test, the Mann-Whitney $U$ test was used. This test is used to evaluate unpaired experiments when comparing two different samples. We test the hypothesis that the two variables have the same probability distribution. At the same time, these variables may not correspond to Gaussian normal distribution; it is sufficient to assume that they are continuous. The test involves the calculation of a statistic, usually called $U$, whose distribution under the null hypothesis is known. $U$ is then given by:

$$
U_{1}=R_{1}-\frac{n_{1}\left(n_{1}+1\right)}{2},
$$

where $n_{1}$ is the sample size for sample 1 , and $R_{1}$ is the sum of the ranks in sample 1 . An equally valid formula for $U$ is:

$$
U_{2}=R_{2}-\frac{n_{2}\left(n_{2}+1\right)}{2}
$$

The smaller value of $\mathrm{U} 1$ and $\mathrm{U} 2$ is the one used when consulting significance Tables. The sum of the two values is given by: 


$$
U_{1}+U_{2}=R_{1}-\frac{n_{1}\left(n_{1}+1\right)}{2}+R_{2}-\frac{n_{2}\left(n_{2}+1\right)}{2}
$$

Knowing that $R_{1}+R_{2}=\frac{N(N+1)}{2}$ and $N=n_{1}+n_{2}$, and doing some algebra, we find that the sum is $U_{1}+U_{2}=n_{1} n_{2}$.

At the same time, the data normality test was always performed using the Shapiro-Wilko test. Fisher's exact test was used to evaluate individual relationships between factors. The tested statistics, where there are two independent selections from alternative distributions, the first has the range $n 1=a+c$ and comes from the distribution $A(\vartheta 1)$, the second has the range $n 2=$ $\mathrm{b}+\mathrm{d}$ and comes from the distribution $\mathrm{A}(\vartheta 2)$. We test the hypothesis H0: $\vartheta 1-\vartheta 2=0$ against the bilateral alternative. Tested statistics (Devore, 2015) are asymptotically driven by the distribution of $N(0,1)$. $\mathrm{M}^{*}$ represents the weighted average of the sample averages. The critical field has a shape (Walker, 2010):

$$
\begin{aligned}
& W=\left(-\infty, u_{1-\frac{\alpha}{2}}\right\rangle \cup\left\langle u_{\left.1-\frac{\alpha}{2}, \infty\right)}\right. \\
& T_{0}=\frac{M_{1}-M_{2}}{\sqrt{M_{*}\left(1-M_{*}\right)\left(\frac{1}{n_{1}}+\frac{1}{n_{2}}\right)}}
\end{aligned}
$$

\section{Empirical data, analysis and results}

\subsection{Size of enterprise and industry in relation to Industry $\mathbf{4 . 0}$}

Into the research, the enterprise size (Stock, \& Seliger, 2016; Frazzon, Hartmann, Makuschewitz, \& Scholz-Reiter, 2013; Trompisch, 2017) and the business sector (Luco, 2019; Muller, 2019; Prause, 2015; Ingaldi, 2020), have been included with respect to the results of the above-mentioned studies proving that the technology maturity of the enterprise is influenced by those two factors. According to the authors, those factors affect the company's approach to the capital, technologies and markets. The main aim of this paper is to evaluate the relationship between the size of the company (evaluated according to the number of employees) in comparison with the development in Industry 4.0. A partial goal is then to evaluate the relationship between the division of enterprises by industry in relation to CZ-NACE again in comparison with developments in Industry 4.0. First, the relationship between enterprise size and Industry 4.0 was examined using a two-sample Mann-Whitney $U$ test at the selected significance level $\alpha=0,05$. The hypotheses $\mathrm{H}_{0}=x 0.50-\mathrm{y} 0.50=0$ were tested, where it is assumed that the influence of these enterprises by Industry 4.0 is the same in both groups and the hypothesis $\mathrm{H}_{A}=x 0.50>\mathrm{y} 0.50$, which assumes that those enterprises unaffected by Industry 4.0 will have fewer employees. In both hypotheses, $X$ represents the companies affected by Industry 4.0 while $Y$ represents the enterprises not affected by Industry 4.0. As shown in Table 1, at the significance level of 0.05 , the null hypothesis in favour of the alternative was rejected based on a p-value very close to zero and a positive $Z$. Therefore, we can argue that companies affected by Industry 4.0 have a higher number of employees. The graphical representation in the form of box plots (Figure 2) also visually confirms this claim. This chart shows the vertical shift of median upwards for enterprises affected by Industry 4.0, both samples having the same minima and maxima, which are given by the criteria for selection of SMEs, (i.e. up to 250 employees). At the same time, the value of the upper quartile is almost twice as high in enterprises affected by Industry 4.0 . 
Table 1 | Mann-Whitney $U$ test calculation - the number of employees and Industry 4.0

Source: authors

\begin{tabular}{l|c|c|c|c|c}
\hline & $\mathbf{U}$ & $\mathbf{Z}$ & $\mathbf{p}$-value & No & Yes \\
\hline $\begin{array}{l}\text { Number of } \\
\text { employees }\end{array}$ & 91739 & 6.7134 & 0.0000 & 389 & 629 \\
\hline
\end{tabular}

Figure 2 | Graphical representation of company size according to the number of employees and Industry 4.0

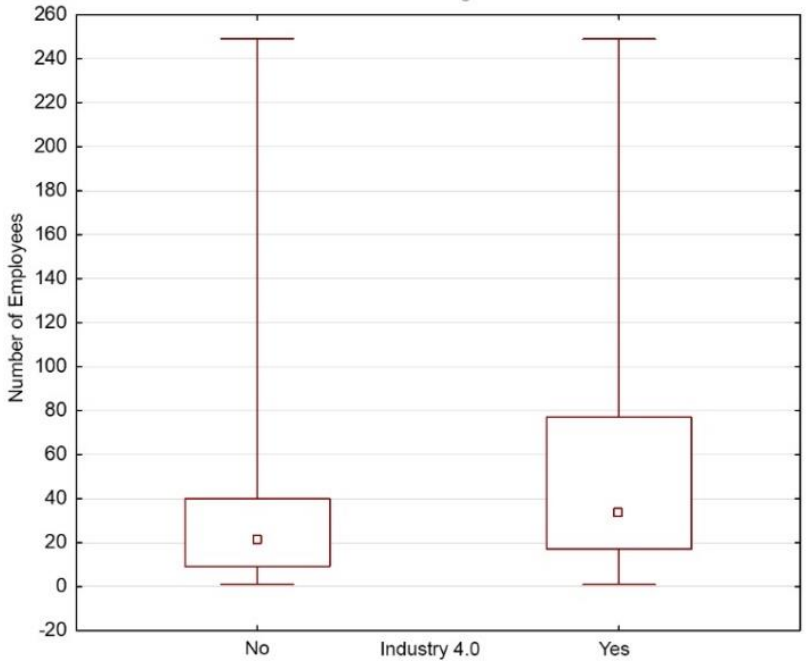

Source: authors

Subsequently, enterprises were divided into seven groups according to CZ-NACE (categories $\mathrm{M}+\mathrm{N}$ - professional and administrative activities, $\mathrm{C}-$ Manufacturing, $\mathrm{J}-$ Information and communication activities, $\mathrm{G}+\mathrm{H}+\mathrm{l}$ - Wholesale, Transport and Accommodation, A Agriculture, $\mathrm{F}-$ Construction and others). Enterprises in all seven groups were further tested using the same statistical methods as a complete sample of 1018 enterprises. The hypotheses were always identical, and the resulting data are summarized in Table 2 below.

Table 2 shows that the size of enterprises does not affect Industry 4.0 in all areas of business. For example, in sectors such as Manufacturing and Information and Communication, along with Professional and Administrative activities, the null hypothesis has not been rejected, as the p-value is always above the significance level, although in many cases it approaches it. On the other hand, in sectors such as Wholesale, Transport, Accommodation represented mainly by business activity, or in Agriculture or in Construction, $\mathrm{H}: 0$ has been rejected in favour of an alternative hypothesis, and we can say that the size of a business in these industries varies with respect to the impact of Industry 4.0 on the company. 
Table 2 | Mann-Whitney $U$ test calculation - the size of the enterprise in individual sectors and Industry 4.0

\begin{tabular}{l|c|c|c}
\hline Number of employees & $\mathbf{U}$ & $\mathbf{Z}$ & P-value \\
\hline M+N Professional and administrative activities & 1562.5 & 1.921 & 0.0547 \\
C Manufacturing & 7788.0 & 1.554 & 0.1202 \\
J Information and communication & 677.0 & 1.589 & 0.1119 \\
G+H+I Wholesale, Transport, Accommodation & 4123.0 & 2.163 & 0.0305 \\
A Agriculture & 183.5 & 3.354 & 0.0008 \\
F Construction & 1164.5 & 2.196 & 0.0281 \\
Others & 1146.0 & 2.052 & 0.0402 \\
\hline
\end{tabular}

Source: authors

Agriculture has been chosen for the graphical representation (Figure 3, the first one), where there are relatively unexpected most striking differences between the companies affected by Industry 4.0, where the median value is 80 employees and the upper and lower quartiles are significantly higher than for those not affected by Industry 4.0, where the maximum values are not used. On the other hand, the manufacturing industry (Figure 3, the second one) did not manage to statistically demonstrate the difference in both groups, but from the box plot below, it can be concluded the median and upper quartile displacement is higher compared to enterprises unaffected by Industry 4.0.

Figure 3 | Graphical representation of the size of the enterprise according to the number of employees in selected industries and Industry 4.0; first Agricultural holdings, second Manufacturing
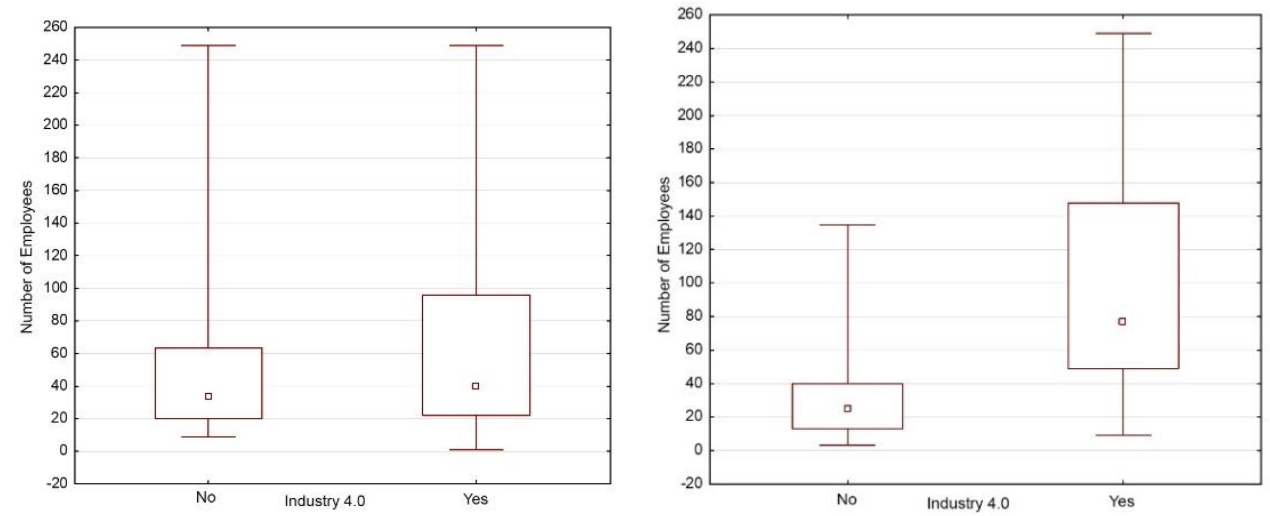

Source: authors

\subsection{Strategic management in relation to Industry 4.0 (detailed by company size and industry)}

The companies were asked among others in the questionnaire, whether they had a written strategy of the company. From the point of view of literature, ideas have been formulated that companies should count on the development of Industry 4.0 already in their long-term strategies. Therefore, the hypothesis concerning the written strategy and the relation of the company to Industry 4.0 is tested here. As can be seen in Table 3 below, 461 SMEs have a written strategy, $70 \%$ of whom also feel affected by Industry 4.0 . On the other hand, $55 \%$ 
of businesses are without a written strategy, of which $45 \%$ do not feel affected by Industry 4.0.

Table 3 | Development of company strategy and Industry 4.0

Source: authors

\begin{tabular}{l|c|c}
\hline Strategy & Industry 4.0 Yes & Industry 4.0 No \\
\hline Written strategy (461) & $32 \%(323)$ & $13 \%(138)$ \\
Non-written strategy (557) & $30 \%(306)$ & $25 \%(251)$ \\
\hline
\end{tabular}

Subsequently, the data were again divided according to the size of enterprises, because in most cases mostly medium and exceptionally small and micro-enterprises have the written strategy as documented by Maříková's research (2018), focused on strategic management of micro-enterprises. In the Table below, enterprises are divided according to the number of employees into three basic categories of SMEs in relation to strategy and Industry 4.0.

Table 4 | Representation of micro, small and medium-sized enterprises with a written strategy and in relation to Industry 4.0

\begin{tabular}{l|c|c|c|c}
\hline $\begin{array}{l}\text { Written } \\
\text { strategy }\end{array}$ & Company size & $\begin{array}{c}\text { Industry } \\
\text { No. }\end{array}$ & $\begin{array}{c}\text { Industry 4.0 } \\
\text { Yes }\end{array}$ & Sum \\
\hline No & Micro & 82 & 70 & 152 \\
Columnar & Micro & $71 \%$ & $71 \%$ & \\
Line & Micro & $54 \%$ & $46 \%$ & \\
Total & Micro & $39 \%$ & $33 \%$ & $71 \%$ \\
\hline Yes & Micro & 33 & 28 & 61 \\
Columnar & Micro & $29 \%$ & $29 \%$ & \\
Line & Micro & $54 \%$ & $46 \%$ & \\
Total & Micro & $15 \%$ & $13 \%$ & $29 \%$ \\
\hline Total & Micro & 115 & 98 & 213 \\
Total & Micro & $54 \%$ & $46 \%$ & $100 \%$ \\
No & Small & 127 & 162 & 289 \\
Columnar & Small & $65 \%$ & $54 \%$ & \\
Line & Small & $44 \%$ & $56 \%$ & \\
Total & Small & $26 \%$ & $33 \%$ & $59 \%$ \\
\hline Yes & Small & 67 & 137 & 204 \\
Columnar & Small & $35 \%$ & $46 \%$ & \\
Line & Small & $33 \%$ & $67 \%$ & \\
Total & Small & $14 \%$ & $28 \%$ & $41 \%$ \\
\hline Total & Small & 194 & 299 & 493 \\
Total & Small & $39 \%$ & $61 \%$ & $100 \%$ \\
No & Medium & 42 & 74 & 116 \\
Columnar & Medium & $53 \%$ & $32 \%$ & \\
Line & Medium & $36 \%$ & $64 \%$ & \\
Total & Medium & $13 \%$ & $24 \%$ & $37 \%$ \\
\hline Yes & Medium & 38 & 158 & 196 \\
Columnar & Medium & $48 \%$ & $68 \%$ & \\
Line & Medium & $19 \%$ & $81 \%$ & \\
Total & Medium & $12 \%$ & $51 \%$ & $63 \%$ \\
\hline Total & Medium & 80 & 232 & \\
Total & Medium & $26 \%$ & $74 \%$ & \\
\hline authors & & & & \\
\hline
\end{tabular}

Source: authors 
Table 4 shows that $71 \%$ of 213 of micro-enterprises do not have a written strategy. Small enterprises have a written strategy in $41 \%$ of cases, here it is interesting that small enterprises are the strongest group (33\%) of those who do not have a written strategy but also feel affected by Industry 4.0, the second largest (28\%) are enterprises with a strategy and affected by Industry 4.0. In terms of medium-sized enterprises, $63 \%$ of enterprises have a written strategy, and at the same time, these enterprises feel the most affected by Industry 4.0 in 158 cases, which is $51 \%$ of all medium-sized enterprises. Subsequently, the companies were compared using Fisher's exact two-tailed test to determine whether the written strategy and influence of Industry 4.0 were not related as the null hypothesis. The results of $p$-values for confirming or rejecting the hypothesis are shown in the table below.

Table 5 | Fisher's test results for SMEs and elaborated strategy

\begin{tabular}{l|c}
\hline \multicolumn{1}{c|}{ SME's size } & P-value \\
\hline Micro-sized enterprise & $\mathrm{p}=0.986$ \\
Small-sized enterprise & $\mathrm{p}=0.015$ \\
Medium-sized enterprise & $\mathrm{p}=0.001$ \\
\hline
\end{tabular}

Source: Own research, authors' processing

The Table 5 shows that the p-value for Fisher's exact two-tailed test is 0.99 for microenterprises, so we cannot reject $\mathrm{H}_{0}$ at the chosen significance level $\alpha=0.05$, and it can still be assumed that the written strategy and the impact of Industry 4.0 on micro business is not related. In contrast, in the case of small and medium-sized enterprises, the null hypothesis has been rejected, wherein both cases the $p$-value is lower than the chosen $\alpha$. It can be said that in these companies, the relationship between the formulated strategy and the influence of Industry 4.0 is statistically significant.

Furthermore, the data were divided according to individual areas of business in SMEs in order to identify deviations and specifics for individual fields. As can be seen from Table 6 below, the distribution of enterprises with a written strategy is very similar in terms of disciplines, except for agriculture, where only $32 \%$ of enterprises have a written strategy compared to, for example, Professional and Administrative activities where enterprises with strategy predominate (52\%).

Table 6 | Formulated strategy and Industry 4.0 by business area

\begin{tabular}{l|c|c|c|c}
\hline \multicolumn{1}{c|}{ Business area } & $\begin{array}{c}\text { Written } \\
\text { strategy }\end{array}$ & $\begin{array}{c}\text { Industry } \\
\mathbf{4 . 0} \mathbf{~ N O}\end{array}$ & $\begin{array}{c}\text { Industry } \\
\mathbf{4 . 0} \text { YES }\end{array}$ & $\begin{array}{c}\text { Sum of } \\
\text { strategy }\end{array}$ \\
\hline M+N Professional and & No & $28.8 \%$ & $19.2 \%$ & $48 \%$ \\
Administrative activities & Yes & $20.0 \%$ & $32.0 \%$ & $52 \%$ \\
C Manufacturing & No & $14 \%$ & $39.2 \%$ & $53 \%$ \\
J Information and Communication & Yes & $6.7 \%$ & $40.1 \%$ & $47 \%$ \\
G+H+I Wholesale, Transport, & No & $37.4 \%$ & $22.9 \%$ & $60 \%$ \\
Accommodation & Yes & $18.1 \%$ & $21.7 \%$ & $40 \%$ \\
A Agriculture & Yes & $25.9 \%$ & $29.8 \%$ & $56 \%$ \\
F Construction & No & $32.14 \%$ & $35 \%$ & $44 \%$ \\
& Yes & $12.5 \%$ & $19.6 \%$ & $32 \%$ \\
\hline
\end{tabular}

Source: authors 
It is also important to note that in the manufacturing industry, of the $47 \%$ of SMEs that have a strategy in place, $86 \%$ feel affected by Industry 4.0, which is the largest of all groups. On the contrary, the least often (55\%), firms in the field of Information and Communication with a strategy feel affected by Industry 4.0, so it can be concluded that there is less influence of Industry 4.0 linked to strategy. Individual areas of business were compared using Fisher's exact two-tailed test, whether the written strategy and impact of Industry 4.0 on the company are not related as a null hypothesis. Table 7 below lists the $p$-values for rejecting or not rejecting the null hypothesis.

Table 7 | Fisher's test results - the relationship between the elaborated strategy and Industry 4.0

Source: authors

\begin{tabular}{l|c}
\hline Business area & p-value \\
\hline M+N Professional and Administrative activities & 0.020 \\
C Manufacturing & 0.009 \\
J Information and Communication activities & 0.177 \\
G+H+I Wholesale, Transport, Accommodation & 0.030 \\
F Construction & 0.337 \\
A Agriculture & 0.580 \\
\hline
\end{tabular}

As the resulting $p$-values indicate, the null hypothesis of the independence of both factors could not be rejected for Information and Communication $(p=0.18)$, Construction $(p=0.34)$, Agriculture $(p=0.58)$. In contrast, $\mathrm{HO}$ was rejected for Professional and Administrative activities $(p=0.02)$, Manufacturing $(p=0.01)$, and Wholesale, Transport, Accommodation $(p=0.03)$. It is, therefore, possible to assume a link in these fields between the elaborated strategy and the influence of Industry 4.0, as also illustrated in Figure 4 below, showing interaction in selected fields. Summing up the previous results, we can conclude that the link between the elaborated strategy and Industry 4.0 has occurred in small and medium-sized enterprises operating in the areas of Professional and Administrative activities and Manufacturing, Wholesale, Transport, Accommodation. The interaction graphs show the relationship of companies to Industry 4.0 on the $\mathrm{X}$-axis and the written business strategy. Yes is highlighted in red, and blue when the business does not have a written strategy. The $Y$ axis shows the individual case frequencies.

Figure 4 | Interaction between the elaborated strategy and the influence of Industry 4.0 in the areas of Professional and Administrative activities (the first one), Manufacturing (the second one) and Construction (the third one)
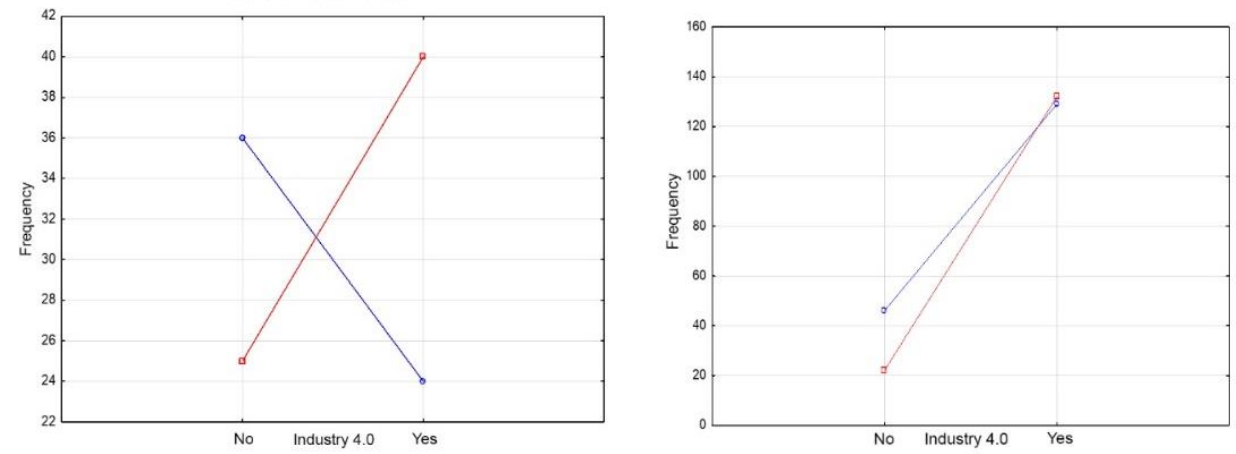


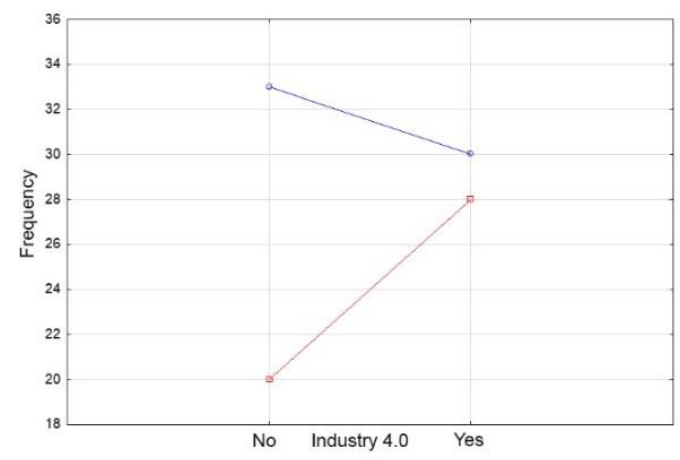

Source: authors

Interesting is the relationship between Professional and Administrative activities, where it is clear from the upper left graph that companies without strategy are not really affected by Industry 4.0. On the other hand, in the upper right graph, which shows the same relationship in Manufacturing, it is evident that enterprises with and without strategy feel the same influence of Industry 4.0. The lower graph shows the construction sector, where the null hypothesis was not rejected, and the independence of both factors can be inferred from the graphical expression.

\section{Discussion and conclusions}

The paper primarily dealt with the analysis of the relationship between enterprise size and Industry 4.0 and the analysis of the relationship between the division of enterprises by industry in relation to CZ-NACE. When evaluating the size of the enterprise, a statistically significant difference was found between the enterprises affected and unaffected by Industry 4.0. Enterprises affected by Industry 4.0 employ more workers, which may be due to the introduction of automation and robotic automation, which means the initial phase, and it is expected that the number of employees will decrease in the future.

The question of the relation between Industry 4.0 and enterprise size or business area, and of the relation between Industry 4.0 and the elaborated strategy have been mention by the other authors only marginally. As it was stated above, e. g. Stock, \& Seliger (2016) say that enterprises with larger and more elaborated organizational structure will have not only more employees but also certainly more elaborated strategy as it was managed to reach in this research by using MNW- test in connection with enterprise size and Industry 4.0. If we adhere to this assumption, we can confirm the hypothesis tested by us that the number of employees in companies affected by Industry 4.0 is higher and similarly in terms of management, companies affected by Industry 4.0 have more often a written strategy. The question is whether a higher number of employees in an industry affected by Industry 4.0 will not only be in the first years of automation and robotization and their share will fall and will only be replaced by manual robot performance and artificial intelligence. In this case, the number of employees in enterprises affected by Industry 4.0 would decrease. If that were the case, we could assume that larger companies with more employees would no longer be significantly affected by Industry 4.0. Frey \& Osborne (2017) developed a scenario that about $47 \%$ of employees in the USA are working in positions that could be replaced over the next 10 to 20 years through automation. If that were the case, this hypothesis would be confirmed. 
The discrepancy of the perception of Industry 4.0 in business sectors may also be caused by different concept of automatization and robotization. For example, in case of smaller agricultural enterprises only smaller systems of manual navigations with the light lath are used (Zhai, 2020), while fully automatic navigational systems are used more in case of larger agricultural enterprises with larger lands or in case of farms specialized in farming more special crops (Rose, 2018). In case of smaller production enterprises, the connection of ERP and MES as it was found out in Hungary (Szalavetz, 2017) is used, or there can be found several automatic product machines and focus on significant innovations (Odei, 2018). While large production companies use more fully automated production lines, which successfully communicate within the supply-customer chains and concurrently are shaded by digital twins (Rojko, 2017) carriers and logistics introduce not only popularized transport drones but already automatic conveyors and sorting lines (Kayikci, 2018; Schlingensiepen, 2016). For that reason, it was necessary to point at different approach in business sectors, so the businessman is able to get a better view and benchmarking in his sector with respect to the enterprise size.

Other practical findings relate to the division of enterprises into seven groups according to the business sector, namely professional and administrative activities; manufacturing industry; information and communication activities; wholesale, transport, accommodation; agriculture; construction and others. Especially in the manufacturing and information and communication industries, we anticipated that there would be a significant statistical difference between enterprises affected by Industry 4.0. There was no statistically significant difference for enterprises in the information and communication sector, but given the definition of Industry 4.0, we would expect a difference in this sector. Surprisingly, however, a difference was found in the wholesale, transport and accommodation sectors, where these results are partly in discrepancy with the research focused on the productivity of work in the connection to the innovations and technologies, where Volek and Novotná (2016) confirmed that companies in the sector wholesales do not focus on innovations. Low usage of technologies in transport sectors has also been confirmed by Pristavka (2016), who has analyzed except quality also the significance of technologies.

As the results further show, the written strategy is largely the domain of medium-sized enterprises, with only $29 \%$ of micro-enterprises and $41 \%$ of small enterprises having it defined. These results are in line with the research by Mařiková (2018), which showed that only $32 \%$ of small and micro-enterprises use strategic management. In contrast, the great importance of the SME strategy, regardless of size, is emphasized by Florea (2014) in his research on Romanian enterprises, where the distribution of strategic management use across all groups of enterprises is similar. According to that how close the authors have analyzed this area, the impact of the strategy on the implementation and application of the principles of Industry 4.0 has not been investigated yet (mainly in the Czechia), so we see the practical benefits in this area, where we can claim that in all sectors except construction, agriculture and information and communication technologies, the relationship between strategy and Industry 4.0 was successfully demonstrated. The significance of the strategic management on the development and technological maturity of agricultural enterprises were confirmed by Chládková and Formánková (2016), the significance of the strategic management on the development and competitiveness at construction companies was confirmed (Flanagan, 2007), where the correlation was confirmed in case of SME and the 
size of the enterprise. Tansey (2018). For that reason, the aim of further research projects is to focus more on the reasons why in these sectors no correlation with Industry 4.0. has been confirmed. The authors of this paper see a big gap in the survey of management in relation to Industry 4.0; therefore, further research will take place in this area.

\section{Acknowledgement}

This paper has been supported by the Faculty of Economics of the University of South Bohemia within the Internal grant competition administrated under the ref. Number EFIGS2017- Vrchota-IGS24B1.

\section{References}

Bahrin, M. A. K., Othman, M. F., Azli, N. N., \& Talib, M. F. (2016). Industry 4.0: A review on industrial automation and robotic. Jurnal Teknologi, 78(6-13), 137-143.

Botha, A. P. (2018). Rapidly Arriving Futures: Future Readiness for Industry 4.0. South African Journal of Industrial Engineering, 29(3), 148-160. https://doi.org/10.7166/29-3-2056.

Bordel, B., \& Alcarria, R. (2017). Assessment of human motivation through analysis of physiological and emotional signals in Industry 4.0 scenarios. Article in Press, Retrieved from Scopus.

Brettel, M., Friederichsen, N., Keller, M., \& Rosenberg, M. (2014). How Virtualization, Decentralization and Network Building Change the Manufacturing Landscape: An Industry 4.0. International Journal of Information and Communication Engineering, 8(1), 8.

Chladkova, H., \& Formankova, S. (2016). Strategy for SMEs in the area of primary agricultural production. Agricultural Economics (Czech Republic), 62(9), 395-406. https://doi.org/10.17221/260/2015-AGRICECON.

Devore, J. L. (2015). Probability and Statistics for Engineering and the Sciences. 9th ed. Boston, MA: Brooks Cole.

Entrialgo, M., Fernández, E., \& Vázquez, C. J. (2000). Linking entrepreneurship and strategic management: Evidence from Spanish SMEs. Technovation, 20(8), 427-436. https://doi.org/10.1016/S0166-4972(99)00168-6.

Esmaeilian, B., Behdad, S., \& Wang, B. (2016). The evolution and future of Manufacturing: A review. Journal of Manufacturing Systems, 39, 79-100. https://doi.org/10.1016/j.jmsy.2016.03.001.

EU Commission. (2006), Definition of SMEs.

Flanagan, R., Lu, W., Shen, L., \& Jewell, C. (2007). Competitiveness in construction: A critical review of research. Construction Management and Economics, 25(9), 989-1000. https://doi.org/10.1080/01446190701258039.

Florea, R., \& Florea, R. (2014). Particular Aspects Regarding Strategic Management Implementation in Romanian SMEs. Economy Transdisciplinarity Cognition; Bacau, 17(2), 30-34.

Frazzon, E. M., Hartmann, J., Makuschewitz, T., \& Scholz-Reiter, B. (2013). Towards Socio-CyberPhysical Systems in Production Networks. In 46th CIRP Conference on Manufacturing Systems 20137 (0), 49-54.

Frey, C. B., \& Osborne, M. A. (2017). "The future of employment: How susceptible are jobs to computerization?" Technological Forecasting and Social Change, Elsevier, vol. 114(C), pages 254-280. https://doi.org/10.1016/j.techfore.2016.08.019.

Gilchrist, A. (2016). Industry 4.0: The Industrial Internet of Things. Bangken: Apress. 
Hatammimi, J., \& Krisnawati, A. (2018). Financial literacy for entrepreneur in the industry 4.0 era: A conceptual framework in Indonesia (s. 183-187). Presented in: ACM International Conference Proceeding Series.

Hitt, M., R. Ireland \& R. Hoskisson. (2011). Strategic Management. Mason: Sou-Western Cengage Learning, Canada.

Ingaldi, M., \& Ulewicz, R. (2020). Problems with the implementation of industry 4.0 in enterprises from the SME sector. Sustainability (Switzerland), 12(1). https://doi.org/10.3390/SU12010217.

Kagermann, H., Lukas, W., Wahlster, W. (2011). Industrie 4.0 - Mit dem Internet der Dinge auf dem Weg zur 4. industriellen Revolution. In: VDI Nachrichten, Issue 13.

Kayikci, Y. (2018). Sustainability impact of digitization in logistics. 21, 782-789. https://doi.org/10.1016/j.promfg.2018.02.184.

Lasi, H., Fettke, P., Kemper, H.-G., Feld, T., \& Hoffmann, M. (2014). Industry 4.0. Business \& Information Systems Engineering, 6(4), 239-242. https://doi.org/10.1007/s12599-014-0334-4.

Lu, Y. (2017). Industry 4.0: A survey on technologies, applications and open research issues. Journal of Industrial Information Integration, 6, 1-10. https://doi.org/10.1016/j.jii.2017.04.005.

Luco, J., Mestre, S., Henry, L., Tamayo, S., \& Fontane, F. (2019). Industry 4.0 in SMEs: A Sectorial Analysis. IFIP Advances in Information and Communication Technology, 566, 357-365. https://doi.org/10.1007/978-3-030-30000-5_45.

Maříková, M. et al. (2018). Selected aspects of strategic management in small enterprises in services.

Mattsson, S., Partini, J., \& Fast-Berglund, Å. (2016). Evaluating Four Devices that Present Operator Emotions in Real-time. 50, 524-528. https://doi.org/10.1016/j.procir.2016.05.013.

Ministry of Industry and Trade. (2011). Report on the Development of Small and Medium Enterprises and its support.

Mintzberg, H., \& Quinn, J. B. (1991). The strategy process: Concepts, contexts, cases. 2nd ed. Englewood Cliffs, N.J: Prentice Hall.

Modrak, V., Soltysova, Z., \& Poklemba, R. (2019). Mapping requirements and roadmap definition for introducing I 4.0 in SME environment. Lecture Notes in Mechanical Engineering, 183-194. https://doi.org/10.1007/978-3-319-99353-9_20.

Mohelska, H., \& Sokolova, M. (2018). Management Approaches for Industry 4.0 - the Organizational Culture Perspective. Technological \& Economic Development of Economy, 24(6), 2225-2240. https://doi.org/10.3846/tede.2018.6397.

Müller, J. M. (2019). Business model innovation in small- and medium-sized enterprises: Strategies for industry 4.0 providers and users. Journal of Manufacturing Technology Management, 30(8), 1127-1142. https://doi.org/10.1108/JMTM-01-2018-0008.

Nayak, S., \& Suhan. (2017). Antecedents to employer branding: A strategic focus on the information technology (IT) sector in India. Polish Journal of Management Studies, 15(2), 143-151. https://doi.org/10.17512/pjms.2017.15.2.13.

Odei, S. A., \& Stejskal, J. (2018). The influence of knowledge sources on firm-level innovation: The case of Slovak and Hungarian manufacturing firms. Central European Business Review, 7(2), 61-74. https://doi.org/10.18267/j.cebr.199.

Obitko, M., \& Jirkovský, V. (2015). Big data semantics in industry 4.0. Lecture Notes in Computer Science (including subseries Lecture Notes in Artificial Intelligence and Lecture Notes in Bioinformatics), 9266, 217-229. https://doi.org/10.1007/978-3-319-22867-9_19. 
Pereira, A. C., \& Romero, F. (2017). A review of the meanings and the implications of the Industry 4.0 concept. In J. Salguero \& E. Ares (Ed.), Manufacturing Engineering Society International Conference 2017, (13, s. 1206-1214). Amsterdam: Elsevier Science Bv.

Pfeiffer, S., \& Suphan, A. (2015): The Labouring Capacity Index: Living Labouring Capacity and Experience as Resources on the Road to Industry 4.0. Working Paper 2015 \#2, University of Hohenheim, Chair for Sociology.

Porter, M. E. (1996). What Is Strategy? Published November.

Prause, G. (2015). Sustainable business models and structures for industry 4.0. Journal of Security and Sustainability Issues, 5(2), 159-169. https://doi.org/10.9770/jssi.2015.5.2(3).

Prinz, C., Morlock, F., Freith, S., Kreggenfeld, N., Kreimeier, D., \& Kuhlenkoetter, B. (2016). Learning Factory modules for smart factories in Industrie 4.0. In K. Martinsen (Ed.), 6th Cirp Conference on Learning Factories (54, 113-118). Amsterdam: Elsevier Science Bv.

Rojko, A. (2017). Industry 4.0 concept: Background and overview. International Journal of Interactive Mobile Technologies, 11(5), 77-90.

Rose, D. C., \& Chilvers, J. (2018). Agriculture 4.0: Broadening Responsible Innovation in an Era of Smart Farming. Frontiers in Sustainable Food Systems, 2. https://doi.org/10.3389/fsufs.2018.00087.

Prístavka, M., Kotorová, M., \& Savov, R. (2016). Quality control in production processes. Acta Technologica Agriculturae, 19(3), 77-83. https://doi.org/10.1515/ata-2016-0016.

Rüßmann, M., Lorenz, M., Gerbert, P., Waldner, M., Justus, J., \& Harnisch, M. (2015). Industry 4.0: The Future of Productivity and Growth in Manufacturing Industries. Retriewed from: http://www.inovasyon.org/pdf/bcg.perspectives_Industry.4.0_2015.pdf.

Safar, L., Sopko, J., Bednar, S., \& Poklemba, R. (2018). Concept of SME business model for industry 4.0 environment. TEM Journal, 7(3), 626-637. https://doi.org/10.18421/TEM73-20.

Schlechtendahl, J., Keinert, M., Kretschmer, F., Lechler, A., \& Verl, A. (2015). Making existing production systems Industry 4.0-ready, Prod. Eng. Res. Devel., 9(1), 143-148.

Schlund, S., Hämmerle, M., \& Strölin, T. (2014). Industry 4.0 - a revolution in work organization. How automation and digitization will change production. Germany, Ulm: Igenics AG. Retriewed from: https://www.ingenics.com/assets/downloads/en/internal/Industrie40_Studie_Ingenics_IAO_en_ VM_Print.pdf.

Schmidt, R., Möhring, M., Härting, R.-C., Reichstein, C., Neumaier, P., \& Jozinović, P. (2015). Industry 4.0 - Potentials for creating smart products: Empirical research results. Lecture Notes in Business Information Processing, 208, 16-27. https://doi.org/10.1007/978-3-319-19027-3_2.

Schuh, G., Potente, T., Wesch-Potente, C., Weber, A. R., \& Prote, J.-P. (2014). Collaboration Mechanisms to Increase Productivity in the Context of Industrie 4.0. Procedia CIRP, 19, 51-56. https://doi.org/10.1016/j.procir.2014.05.016.

Stock, T., \& Seliger, G. (2016). Opportunities of Sustainable Manufacturing in Industry 4.0. Procedia CIRP, 40, 536-541. https://doi.org/10.1016/j.procir.2016.01.129.

Szalavetz, A. (2017). The environmental impact of advanced manufacturing technologies: Examples from Hungary. Central European Business Review, 6(2), 18-29. https://doi.org/10.18267/J.CEBR.177.

Tansey, P., \& Spillane, J. (2018). Vistas of strategy-making within Northern Ireland construction firms: How SME's differ from large firms. 776-785. Retriewed from Scopus. 
Trompisch, P. (2017). The implications of Industry 4.0 on the future of work. Elektrotechnik Und Informationstechnik, 134(7), 370-373. https://doi.org/10.1007/s00502-017-0531-1.

Volek, T., \& Novotna, M. (2016). Labour Productivity as a Factor of Sector Competitiveness. 10th International Days of Statistics and Economics, 1997-2006.

Walker, I. (2010). Research Methods and Statistics. Houndmills, Basingstoke. Hampshire; New York, NY: Palgrave.

Wienbruch, T., Leineweber, S., Kreimeier, D., \& Kuhlenkoetter, B. (2018). Evolution of SMEs towards Industrie 4.0 through a scenario based learning factory training. In D. Mourtzis \& G. Chryssolouris (Ed.), 8th Cirp Sponsored Conference on Learning Factories (clf 2018) - Advanced Engineering Education \& Training for Manufacturing Innovation (23, 141-146). Amsterdam: Elsevier Science Bv.

Zhai, Z., Martínez, J. F., Beltran, V., \& Martínez, N. L. (2020). Decision support systems for agriculture 4.0: Survey and challenges. Computers and Electronics in Agriculture, 170. https://doi.org/10.1016/j.compag.2020.105256.

Zhong, R. Y., Xu, X., Klotz, E., \& Newman, S. T. (2017). Intelligent Manufacturing in the Context of Industry 4.0: A Review. Engineering, 3(5), 616-630. https://doi.org/10.1016/J.ENG.2017.05.015.

Zhou, K., Liu, T., \& Zhou, L. (2015). Industry 4.0: Towards future industrial opportunities and challenges. In 2015 12th International Conference on Fuzzy Systems and Knowledge Discovery (FSKD), 2147-2152. https://doi.org/10.1109/FSKD.2015.7382284.

The research paper passed the review process. | Received: January 21, 2020; Revised: March 21, 2020; Accepted: April 17, 2020; Published: September 30, 2020. 